a rule, sprung from an intellectual stock, with a history in the family, often of gout, eczema, or migraine. Thin and meagre, they exhaust their little bodies by the energy they throw into all the activities of life. The body is apt to be ill-braced with muscle and there is often a tendency to flat feet, knock-knee, lordosis, enteroptosis, round shoulders, and flattened chest-often kidney-shaped on cross section. Their pallor is usually a cause of alarm to the parents. The blood falls readily away from the face, leaving it drawn and wornlooking. Abdominal pain or discomfort, attacks of utter prostration marked often by extreme nervous irritability, and sometimes by the classical cyclical vomiting, are the rule. Often the body temperature shows a persistent instability for weeks or months together. The heart's action is excitable and the response to exercise bad. Functional murmurs and extra-systoles are common. Fears of tuberculosis, of chronic appendicitis, and of subacute rheumatism are commonly aroused. Complaint is often made of extreme nervousness. The appetite is usually bad. Children of this type are often inveterate cold-catchers. All the vasomotor defences against chill are ill-developed and unstable.

In general the catarrhal infection is marked, not by the severity of the local reaction in nose and throat, but by the way in which the liver appears to be caught up and involved in the disturbance. In any household in which the members are suffering from some acute infective catarrh, the child of this type will react to the infection, not as the others, but by showing one of the typical " sick attacks" or attacks of pallor, prostration, persistent slight fever, and anorexia. In these children sometimes the underlying infection may be altogether masked by the severe gastric or hepatic disturbance. A diet poor in fat but rich in sugar and starch, a daily apéritif of some alkaline or laxative saline, and the provision of sufficient rest will do much to improve the physique and resistance to infection. Hydrotherapy, hot and cold douching alternatively, skin friction, massage and physical exercises, all serve to improve the tone of the blood-vessels. Hot and cold douching, followed by friction, is especially successful in preventing the tendency to excessive night-sweating which so many of the children show and which is at times no doubt responsible for the cold-catching. The attempt to improve the nutrition by prescribing much milk, cream, butter, \&c., always fails.

Our old friend the veracious historian narrates how that at a recent clinic in one of our well-known British postgraduate centres the physician was discussing in the ward a case of erythema nodosum with his practitioner-students, but said nothing about its treatment. It was respectfully hinted to him that that was indeed the case, but without result. Yet again, after an appropriate interval the suggestion was made, and this time a little more strongly, that something in this direction would be highly acceptable, whereupon he gravely said that the treatment was likewise "nodose."

\section{RENAL DISEASE :}

\section{SOME POINTS IN TREATMENT.*}

BY

J. W. McNEE, M.D. GLasG., F.R.C.P. Lond., DFPUTY DIRECTOR OF THE MEDICAL UNIT, UNIVERSITY COLLEC HOSPITAL; PHYSICIAN (IN CHARGE OF OUT-PATIENTS),
ROYAL NORTHERN HOSPITAL.

ON such a wide subject only a few matters of $\stackrel{\mathbb{D}}{\varrho}$ practical interest can be discussed in this lecture, and I wish therefore to lay stress on certain points $\vec{P}$ in renal disease which are frequently not placed in the prominent position they deserve. I intend to $\vec{\omega}$ deal with the treatment of " nephritis," although that word even when governed by various descrip- 6 tive adjectives may be unsuitable to describe 3 . accurately all the conditions included under that $-\vec{v}$ term.

I am, as you all must be, very familiar with recent $t_{0}^{N}$ work on methods of estimating the renal function 5 in different forms of nephritis. This work, both $\vec{P}$ here and elsewhere, must, I think, be admitted to be somewhat disappointing in the purely practical results, both as regards prognosis where this is $\overrightarrow{0}$ most needed and as regards indications for treat- $\%$ ment. The cases where renal efficiency tests indicate a bad prognosis are often those in which clinical observation drives the physician to the same conclusion. Some patients from whom little information is obtained are just those instances $\mathbb{D}$ in which help in prognosis is urgently required. $\stackrel{\circ}{\vec{F}}$ Repetition of certain tests at intervals may, however, be of great service in indicating improve- $\frac{3}{2}$ ment or the reverse, and may in that way considerably influence treatment.

The reason for the frequent inability of such tests $\frac{2}{3}$ to give the information desired by the clinician is well known. The kidneys are seldom uniformly and 3 . permanently damaged in all their secreting tissues, $ᄋ$ and we know that a large amount of renal tissue must be out of action before actual insufficiency 0 results. It is known that the renal glomeruli, and presumably also the tubules connected with them, 을 are active for short periods in groups, then rest while others take on the function. Thus only a part of $\stackrel{N}{\sigma}$ the renal tissues is active at any one time. Very $N$ many tubules and glomeruli must be completely $\mathrm{C}_{\mathrm{N}}$ out of action to prevent those remaining healthy 0 from carrying on adequate renal secretion, at least for a while. The only difference is that the secreting tissues have insufficient rest. In the normal $\stackrel{\Phi}{\oplus}$ kidneys a very ample margin of safety has been ${ }_{0}$ provided, and we know how absolutely negligible ${ }_{0}^{-}$ is the result of removing one entire kidney when $\mathbb{\mathbb { D }}$ the other is sound. During the war I examined the $\frac{}{\mathbb{1}}$ kidneys of young soldiers who had died quickly from $\cong$ severe wounds, and in every instance a few sclerosed glomeruli could be made out in microscopic sections.

- A Post-Graduate Lecture delivered to the Fellowship o Medicine on Feb. 4th. 
This means that in every healthy person some glomeruli with their corresponding tubules are destroyed from time to time and not replaced; it may be as a result of the otherwise trivial infections from which none of us escapes.

For me, at least, one of the most interesting points emerging from recent work on renal disease is that for clinical purposes the only possible classification, at present, of the more chronic varieties of nephritis is into the so-called "hydræmic" and " azotæmic" varieties-the one with salt retention, œdema and abundant albuminuria, the other with nitrogen retention, and often with very slight œdema and albuminuria. These two divisions govern us at present as regards all our main lines of treatment of chronic nephritis. Acute nephritis may quite simply be regarded as a combination of both varieties.

\section{ACUTE NePhritis.}

The ætiology and treatment of acute nephritis has interested me greatly since I saw so much of the condition in France. Let me say that it is not sufficiently realised that exactly the same disease in all its clinical aspects, with the same histological picture of an acute glomerulo-nephritis in the fatal cases, occurs in civil life. I have examples to show you both of the so-called war or trench nephritis and of the same condition in civil life.

The treatment of acute nephritis is particularly important. We know from what happened during the war to the thousands of cases of acute glomerulonephritis, that complete healing of the renal damage, with disappearance of all signs, like albuminuria, is to be expected in a large proportion of the sufferers. Many men who had nephritis during the war are now perfectly well and healthy ten years afterwards. This is not to be wondered at when the histology of the damaged kidneys in the fatal cases is considered, nearly 70 of which were examined by Shaw Dunn and myself. There are, in the acute stages, no fixed-tissue cell changes (fibrosis, \&c.) at all ; no cellular changes, in fact, which cannot be fully recovered from without leaving a permanent scar. The greater number of such cases of acute nephritis seen in practice should cure and heal completely, and all treatment should be directed to the full completion of healing before it is relaxed.

Let us consider cases of acute nephritis as ordinarily seen. They commonly occur in children or young adults, often as a sequel of acute tonsillitis or some other local acute infection. Albuminuria is copious; hæmaturia frequent. Edema occurs, either slight or extreme. All the functional activities of the kidney are deranged, and nitrogen and salt are retained in varying degree.

I have watched a number of such cases in the past few years, especially in a children's ward. The treatment may have to be continued for many months, the aim always being to await complete healing and complete freedom from albuminuria. It is easy in many instances to get rapid improvement and a good output of urine, with the albumin diminished to $\frac{1}{2}$ per cent. in the Esbach tube. But there, unfortunately, the progress is often arrested, and albuminuria persists for months and months: Is this albuminuria dangerous, and does it mean that permanent and irrecoverable damage to the kidneys has ensued? I think not, because in such cases, even when granular tube-casts accompany the albuminuria, the albumin and casts may later completely disappear after continued care in treatment. I feel sure that the physician must not " let go " in such patients, but persist in his care for many months until cure results, or until other evidence reluctantly drives him to the conclusion that the albuminuria is a sign of progressive and permanent renal disease. One way in which this latter unfortunate fact may be recognised early is that tube-casts containing cholesterol-ester fats, doubly refracting to light when viewed through crossed Nicol's prisms under the microscope, may appear. Given a previous acute nephritis, fatty casts of this special kind indicate strongly the secondary degenerative changes in the tubular epithelium which occur in the progressive forms of nephritis.

Two further points in a general way may be referred to in connexion with the treatment of acute nephritis. It may be very important in patients in whom the albuminuria does not clear up to remove septic tonsils, especially if tonsillitis preceded the onset of the disease, but even apart from that.

No one who has examined the kidneys removed from the body in a fatal case of acute nephritis can fail to be struck with the way in which the capsule is tightly stretched out over the swollen kidney. This pressure must add greatly to the difficulties of the damaged kidney, and theoretically in such cases splitting or removal of the capsule ought to do much good. It is so difficult, however, for the physician to decide in a patient critically ill that such an operation must be undertaken to give the patient a chance, that it is not to be wondered at that this operation is infrequently performed. A much clearer indication is when suppression of urine occurs in acute nephritis, then this operation may afford the only chance of recovery. I am certain that the old practice of hot packs and of dry cupping, or even wet cupping, over the loins in cases of acute nephritis, with great diminution in urinary output, has fallen into undeserved neglect. There is an impression that it is unscientific and empirical, but since Pavlov has attempted scientific explanation of the action of counter-irritants it may be hoped that clinicians will return to some of these old remedies, a few of which (for example, turpentine stupes) have never been completely eliminated.

Other points in the treatment of acute nephritis will be covered in dealing with chronic nephritis, to which I now turn. 


\section{Chronic Nephritis.}

I have no intention of going over the ordinary lines of treatment of chronic nephritis given in the text-books. It is far better to give entirely personal views and emphasise personal beliefs.

Two points in treatment are, I believe, of special importance and both are, unfortunately, at present beset with difficulties. These are the influence of diet-solids and liquids-in treatment, and the employment of diuretics to remove œdema. The first of these methods assumes particular importance in patients having nephritis with nitrogen retention ; the use of diuretics is specially urgent in cases with œdema and large effusions into pleuræ and peritoneum. It may be said at once that the scientific basis of both of these forms of treatment is far from understood, and the procedure is thus largely a matter of trial and error. Often there is a "miss," sometimes a remarkable and satisfactory "hit."

Diet.-When I think over my recent experiences in the United States of America, I feel that we in Britain are now greatly behindhand in exploiting dietetic measures in the treatment of disease. Only the recent developments in diabetic therapy have roused us, but still in a sadly limited way. I am not recommending special dietetic régimes, such as the Epstein diet, in the treatment of nephritis, but dietetic measures of a more general kind. An excellent account of the dietetic principles involved in the treatment of nephritis is given by Christian and O'Hare in their revised chapters for the "Oxford Medicine" (Christian and Mackenzie). No extremes are advocated in protein or fluid intake. The main principles are as follows. In the early acute stage milk only, $800-1000 \mathrm{c.cm}$., is given, or occasionally bread and milk. After this stage is over, the diet should be of increased caloric value with a low content in protein and salt. The caloric value is mainly made up by carbohydrate and fat. The "low protein, salt poor" diet used by Christian in Boston is constructed to comprise 2000 calories, with not more than $25 \mathrm{~g}$. of protein and $2 \mathrm{~g}$. of sodium chloride. The fluid intake is fixed at 1200 to 1500 c.cm. in the 24 hours. As convalescence progresses protein is gradually added until $75 \mathrm{~g}$. per day is reached, but no more is given until all evidence of nephritis has disappeared.

I am emphatic that such care in dietetics yielded to me better results in cases of nephritis than I am accustomed to expect at home, where the dietetics in hospital and private practice are much more haphazard.

Diuretics.-The profession at present is much in need of guidance in the mechanism and use of diuretic drugs. New drugs are constantly being advocated (novasurol, ammonium chloride), but it is difficult to form any just estimate of their value. The fact is, as I have indicated, that with our very imperfect knowledge of urinary secretion both in health and disease, the use of diuretic drugs is still largely on the " hit-and-miss" principle. A drug acts like a charm in one patient and is valueless ino the next. This being so, the only method available to us is to give one drug after another a fair tria over a reasonable time, beginning with the simples remedies which can do least harm, if they happer. to do no good. In order these might perhaps be roughly placed : plain water, caffein, urea, various? theobromin derivatives (diuretin, \&c.), theocin and finally drugs like novasurol and calcium of ammonium chloride. I must not, of course, omif the use and great value of digitalis in cases of nephritis with œdema due to secondary cardio vascular changes. In some cases gastric irritability will defeat some of these drug treatments, and the remedy will be vomited at once, as in $\overrightarrow{a_{\omega}}$ recent case where ammonium chloride was beinge tried.

The value of venesection should not be forgotten $\frac{3}{3}$. and I have seen copious diuresis follow the removat of blood without any drug being employed at allio It is, however, only too well known that so-called " urinary crises," with extraordinary diuresis andF clearing up of odema may begin without any active treatment whatever!

I would emphasise again that I have deliberately omitted all points in treatment which are adequately dealt with in text-books and have tried to speak of some matters which are of great importance in the general management of nephritis, but not sos commonly described.

THE RÔLE OF VACCINE THERAPY IN COLIFORM INFECTIONS OF THE URINARY TRACT.

BY

T. H. C. BENIANS, F.R.C.S. ENG., PATHOLOGIST TO THE PRINCE OF WALFS'S AND NORTH MIDDLESEX HOSPITALS.

THIs has been a debatable subject since thळ commencement of vaccine therapy. Cases claimed as wonderful successes and still more numerous ones that have been abject failures have fallen to the lot of almost everyone who has practised this treatment. It ought therefore to be of interest to consider some of the anatomical and immunological? data that appear to operate and govern the results of treatment.

\section{Method of INFECTION.}

This must be considered on account of the constant liability to relapse in this class of infecr tion, since these relapses constitute, in a sense, reinfection. Bacteria of the coli-typhoid group have been shown to have a remarkable facility foo passing into the blood stream from the tissues, n⿳亠े 